Article

\title{
Detection of Occult Metastases in Patients with T1 and T2 Stage Lower Lip Squamous Cell Carcinomas after Positive Lymphoscintigraphy
}

\author{
Mergime Prekazi Loxha ${ }^{1}$, David Stubljar ${ }^{2, * \mathbb{D}}$, Tomislav Jukic ${ }^{3}$ and Sinan Rusinovci ${ }^{1}$ \\ 1 Department of Maxillofacial Surgery, Faculty of Medicine Pristina, 10000 Pristina, Kosovo; \\ mergimeloxha@gmail.com (M.P.L.); sinan.rusinovci@gmail.com (S.R.) \\ 2 Department of Research and Development, In-Medico, 8330 Metlika, Slovenia \\ 3 Department of Internal medicine, History of Medicine and Medical Ethics, Faculty of Medicine, Josip Juraj \\ Strossmayer University of Osijek, 31000 Osijek, Croatia; jukic.tomi@gmail.com \\ * Correspondence: d.stubljar@gmail.com
}

Received: 24 January 2020; Accepted: 9 February 2020; Published: 11 February 2020

\begin{abstract}
The aim of this study was to detect lower lip squamous cell carcinomas (SCC) that had metastasized to the lymph nodes and to evaluate if neck dissection was necessary for patients with $\mathrm{T} 1$ or T2-stage lip cancer after a sentinel lymph node biopsy (SLNB). The study was conducted as a prospective clinical study to detect occult neck metastases in patients with T1 or T2 stage SCC of the lower lip. Thirty-one patients were eligible and underwent echo-ultrasound, computer tomography, magnetic resonance and lymphoscintigraphy (LSG) as diagnostic procedures. LSG was performed on the same day as the surgical procedure, after intradermal injection of $37 \mathrm{Mbq}$ Tc99m-Sn-colloid/mL at four peritumoral sites. In patients with positive LSG results, the sentinel lymph nodes were extracted surgically. The risk factors for cancer development were sun exposure and smoking. The highest accuracy for detecting lymph node enlargements was achieved with magnetic resonance imaging (MRI; $80.7 \%$ ). LSG showed excellent sensitivity (100\%) and negative predictive value (NPV; $100 \%)$. Overall, occult metastases were diagnosed with an SLNB in eight (25.8\%) patients. According to the results, with great caution, we suggest that an SLNB is reasonable to initiate only for patients with positive sentinel nodes by positive LSG, to be used as a lower morbidity approach for selected patients with $\mathrm{T} 1$ and $\mathrm{T} 2$ stage cancers.
\end{abstract}

Keywords: squamous cell carcinoma; lower lip; lymphoscintigraphy; metastasis; sentinel lymph node biopsy

\section{Introduction}

Squamous cell carcinoma (SCC) of the lower lip accounts for $25 \%$ of all oral cancers [1,2]. It is an epithelial malignant, infiltrating and destructive tumor with metastatic potential that can invade the deep muscle and mandible and can metastasize to the neck lymph nodes or blood [3]. Regional metastases rates vary and could be present in $5 \%$ to $20 \%$ of cases, and their presence reduces the prognosis to $50 \%$ [4]. SCC of the lips can develop at any position along the upper or lower lip, but $90 \%$ of all cases involve the lower lip [5]. It is more frequent in male than female patients; patients aged over 45 years; those with chronic sun exposure, and chronic smoking and alcohol-drinking habits [1,6]; and in patients with accompanied systemic lupus erythematosus $[7,8]$.

SCC tumors are not acknowledged as fatal [9-12]. Surgical excision of a primary tumor achieves a 5 -year cure rate of $92 \%$, with an overall recurrence rate of only $8 \%$ [13]. The mean survival rate of patients is $90 \%$ at 2 years and $83 \%$ at 5 years. However, patients with a T3 or T4 stage SCC and those with metastases have an unfavorable prognosis [3]. The five-year overall survival of patients 
with regional metastases ranges from $25 \%$ to $70 \%$ [14]. After treatment, patients must be examined and followed-up for at least 5 years to find possible recurrences and potential regional metastases. Almost $75 \%$ of metastasis appear in the first year after surgery, a period in which examinations must be periodic, more frequent, and accurate [3].

Surgical procedures play an important treatment role in SCC management. Surgery includes full tumor excision, lymph node dissection, and simultaneous reconstruction $[15,16]$. One of the characteristics of lips SCC is the extension of the tumor, which can manifest either towards the surface, in depth or in both directions. For instance, the occult metastases rates of a T2 stage lip cancer were reported in $15 \%$ to $35 \%$ of cases [17]. In such cases, elective neck dissection with excision of the primary tumor is the treatment of choice [18]. However, not every patient should be recommended for elective neck dissection. The presence of lymph node metastases is the main prognostic factor; however, most diagnostic methods used to detect susceptible metastases in the neck are not accurate. Computer tomography (CT), magnetic resonance imaging (MRI) and ultrasound can detect lymph nodes but not metastases. Therefore, sentinel lymph node biopsy (SLNB) is the most advisable option to diagnose metastases in the neck lymph nodes, especially in patients with N0 [17], and it may help in the treatment of these patients [19]. SLNB, as one of the procedures, is standard care for melanoma [20]. However, the data on patients with nonmelanoma skin cancers (NMSC) are sparse [21,22]. The patients with NMSC, such as SCC, show lymph node metastasis [9,23,24], but to our knowledge there has been no report of a relatively large number of patients followed in a prospective study. Therefore, it is vital to collect data on SLNB in SCC cases and examine its accuracy.

In the current study, we focused on analyzing patients who were suffering from stage T1 and T2 of SCC of the lower lip. Moreover, metastatic tumors through a 2-year follow-up period were also detected using SLNB. Thus, our study aimed to analyze lower lip SCC tumors that had metastasized to the lymph nodes, to evaluate the accuracy of diagnostic tools for lymph node enlargements (echo-ultrasound, magnetic resonance imaging (MRI), CT and lymphoscintigraphy (LSG)), and show if elective or supraomohyoid neck dissection was necessary for patients with T1 or T2-stage lip cancer, to evaluate the applicability of the SLNB concept for T1 and T2 SCC of the lower lip.

\section{Materials and Methods}

The study was conducted as a prospective clinical study to detect occult neck metastases in patients with T1 or T2 stage squamous cell carcinoma (SCC) of the lower lip. Patients were treated at the Department of Maxillofacial Surgery at the University Clinical Centre of Kosovo and followed for 2 years. The research was conducted in full accordance with the medical protocols of the Declaration of Helsinki. Patients gave their written consent for collaboration in the study. The Institutional Ethics Committee of the Faculty of Medicine, University of Pristina approved the study design (document Nr.1551, 30.03.2010).

The inclusion criteria for patients to participate were aged 18 years and older, detected SCC of the lower lip with TNM classification cT1 and cT2 and with an indication for surgical intervention. Patients were excluded when treated with radiotherapy before surgery, with recurrent carcinoma, or with stage T3 and T4 lower lip carcinoma. Overall, 31 patients were eligible for inclusion in the analysis.

Eligible patients underwent echo-ultrasound, computer tomography (CT), magnetic resonance (MRI) and lymphoscintigraphy (LSG) as diagnostic procedures. At enrolment, clinically relevant data (including exposure to potential risk factors such as sun exposure, alcohol and tobacco use, and family history) were collected. Clinical examination of the oral cavity and oropharynx was performed in all patients. LSG of the neck was performed to detect lymph nodes in the neck. LSG was performed on the same day as surgical procedure, after intradermal injection of $37 \mathrm{Mbq}$ Tc $99 \mathrm{~m}$-Sn-colloid/mL at four peritumoral sites. In patients with positive LSG results, sentinel lymph nodes were extracted surgically. The extracted nodes were sent for histopathological analysis to confirm cancer metastases. 


\section{Results}

Out of the 31 patients enrolled in the study, the majority were men $(n=28 ; 90.3 \%)$. The mean age of the patients in the present study was $61.6 \pm 13.4$ years, as shown in Table 1 . More than half of the patients $(n=19 ; 61.3 \%)$ were 60 years of age and older. According to the age distribution, a positive diagnosis of SCC of the lower lip was detected at two peaks. Most often, the cancer occurred in patients aged 60-69 and 70-79 years, as shown in Figure 1. Almost half $(45.2 \%)$ of all patients were farmers by profession.

Table 1. The basic characteristics of patients with lower lip cancer.

\begin{tabular}{cc}
\hline & Patients $(n=31)$ \\
\hline Age (years) & $61.6 \pm 13.4$ \\
Gender & $28(90.3 \%) / 3(9.7 \%)$ \\
M/F & \\
Profession & $14(45.2 \%)$ \\
Farmer & $1(3.2 \%)$ \\
Housewife & $3(9.7 \%)$ \\
Machinist & $6(19.4 \%)$ \\
Pensioner & $6(19.4 \%)$ \\
Physical worker & $1(3.2 \%)$ \\
Police officer &
\end{tabular}

$\mathrm{M}-$ male, F-female.

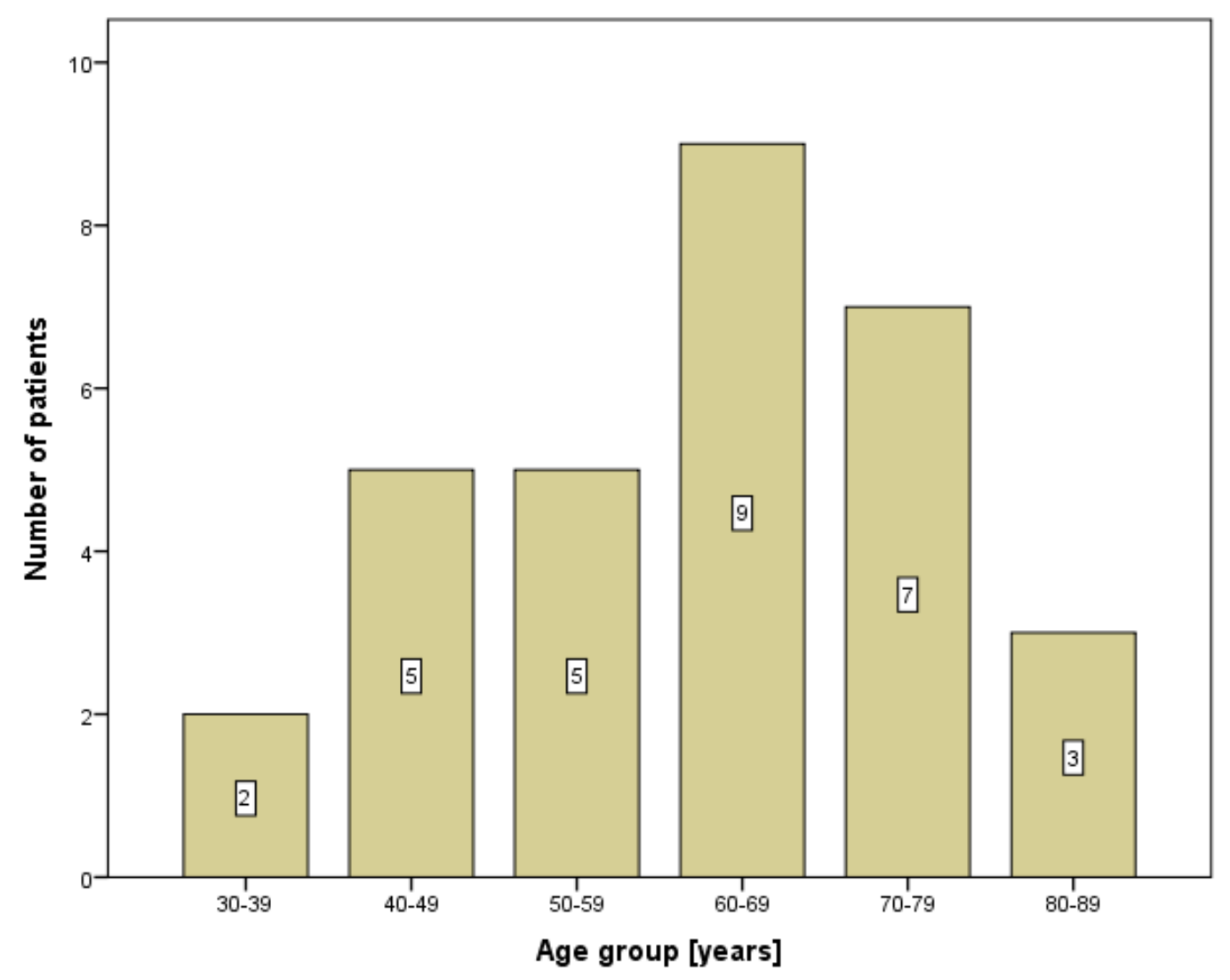

Figure 1. The age distribution of patients with lower lip cancer.

The characteristics of the cancers are presented in Table 2 . The majority of patients $(n=22 ; 71.0 \%)$ had stage T1 SCC. Lymph node enlargements were discovered in 10 patients. Approximately half of the patients suffered the disease for more than 1 year. The most frequent risk factors for cancer development were sun exposure and smoking; meanwhile, alcohol use and family history were not so 
frequent. There were no statistical differences in patients' basic characteristics and cancer characteristics between genders (data not shown).

Table 2. The characteristics of squamous cell carcinoma (SCC) of the lower lip and diagnostic procedure findings.

\begin{tabular}{cc}
\hline & Patients $(n=31)$ \\
\hline TNM classification & \\
Tc1Nc0M0 & $16(51.6 \%)$ \\
Tc1Nc1M0 & $6(19.4 \%)$ \\
Tc2Nc0M0 & $5(16.1 \%)$ \\
Tc2Nc1M0 & $4(12.9 \%)$ \\
Tumor size & \\
T1 & $22(71.0 \%)$ \\
T2 & $9(29.0 \%)$ \\
Lymph node enlargement & $10(32.3 \%)$ \\
Risk factors & \\
Sun exposure & $15(48.4 \%)$ \\
Smoking & $22(71.0 \%)$ \\
Alcohol & $6(19.4 \%)$ \\
Family history & $5(16 \%)$ \\
Duration of pathology & \\
Under 1 year & $14(45.2 \%)$ \\
Over 1 year & $17(54.8 \%)$ \\
Positive echo & $13(41.9 \%)$ \\
Positive MRI & $12(38.7 \%)$ \\
Positive CT & $2(6.5 \%)$ \\
Positive LSG & $21(67.7 \%)$ \\
Submental region & $6(28.6 \%)$ \\
Submandibular region & $2(9.5 \%)$ \\
Both regions & $13(61.9 \%)$ \\
\hline
\end{tabular}

Echo—echo-ultrasound, MRI—magnetic resonance, CT—computer tomography; LSG—lymphoscintigraphy.

Positive lymph enlargements were detected in 10 patients (32.3\%). Meanwhile, positive ultrasound, MRI, CT and LSG were detected in 13, 12, 2 and 21 patients, respectively, as shown in Table 2. Among 21 positive LSG patients, the majority had lymph node enlargements in both submental and submandibular regions. No potential risk factors were detected that could be statistically associated with the prediction of lymph node enlargements, as shown in Table 3.

Table 3. The potential risk factors for lymph node enlargements.

\begin{tabular}{cccc}
\hline & $\begin{array}{c}\text { No Enlargement } \\
(\boldsymbol{n}=\mathbf{2 1})\end{array}$ & $\begin{array}{c}\text { Lymph Node } \\
\text { Enlargement }(\boldsymbol{n = 1 0 )})\end{array}$ & $\boldsymbol{p}$-Value \\
\hline Age (years) & $60.2 \pm 12.7$ & $64.6 \pm 15.1$ & 0.407 \\
Gender & & & 0.180 \\
M/F & $20 / 1$ & $5 / 2$ & 0.960 \\
Profession & $9(42.9 \%)$ & $5(50.0 \%)$ & \\
Farmer & $1(4.8 \%)$ & 0 & \\
Housewife & $2(9.5 \%)$ & $1(10.0 \%)$ & \\
Machinist & $4(19.0 \%)$ & $2(20.0 \%)$ & \\
Pensioner & $4(19.0 \%)$ & $2(20.0 \%)$ & \\
Physical worker & & &
\end{tabular}


Table 3. Cont.

\begin{tabular}{cccc}
\hline & $\begin{array}{c}\text { No Enlargement } \\
(\boldsymbol{n = 2 1 )}\end{array}$ & $\begin{array}{c}\text { Lymph Node } \\
\text { Enlargement }(\boldsymbol{n = 1 0 )})\end{array}$ & $\boldsymbol{p}$-Value \\
\hline Police officer & $1(4.8 \%)$ & 0 & 0.353 \\
Tumor size & $16(76.2 \%)$ & $6(60.0 \%)$ & \\
T1 & $5(23.8 \%)$ & $4(40.0 \%)$ & 0.901 \\
T2 & $10(47.6 \%)$ & $5(50.0 \%)$ & 0.353 \\
Sun exposure & $16(76.2 \%)$ & $6(60.0 \%)$ & 0.363 \\
Smoking & $5(23.8 \%)$ & $1(10.0 \%)$ & 0.522 \\
Alcohol & $4(19.0 \%)$ & $1(10.0 \%)$ & 0.052 \\
Family history & $12(57.1 \%)$ & $2(20.0 \%)$ & \\
Duration of pathology & $9(42.9 \%)$ & $8(80.0 \%)$ & \\
Under 1 year & & &
\end{tabular}

We were also interested in observing which diagnostic tool could potentially predict positive lymph node enlargement. Table 4 and Figure 2 present the values of receiver operating characteristic curve (ROC) analysis for detecting lymph node enlargement. The highest accuracy was found with MRI (80.7\%). Meanwhile, LSG showed excellent sensitivity $(100 \%)$ and negative predictive value (NPV; $100 \%$ ) value but due to a high count of false-positive results ( $n=11$ cases) was lower on specificity and PPV.

Table 4. The values of the receiver operating characteristic curve (ROC) analysis to detect lymph node enlargements (calculated area under curve, sensitivity, specificity and predictive values) for different diagnostic tools.

\begin{tabular}{ccccccccc}
\hline & $\begin{array}{c}\text { Lymph Node } \\
\text { Enlargement } \\
(\boldsymbol{n}=\mathbf{1 0})\end{array}$ & $\begin{array}{c}\text { AUC } \mathbf{( 9 5 \%} \\
\mathbf{C I})\end{array}$ & Sn & Sp & PPV & NPV & Accuracy & $\boldsymbol{p}$-Value \\
\hline Echo-ultrasound & $8(80 \%)$ & $\begin{array}{c}0.781 \\
(0.600-0.962) \\
0.805\end{array}$ & $80.0 \%$ & $86.2 \%$ & $61.5 \%$ & $88.9 \%$ & $77.4 \%$ & 0.013 \\
MRI & $8(80 \%)$ & $\begin{array}{c}(0.629-0.980) \\
0.526\end{array}$ & $80.0 \%$ & $81.0 \%$ & $66.7 \%$ & $89.5 \%$ & $80.7 \%$ & 0.007 \\
CT & $1(10 \%)$ & $\begin{array}{c}(0.302-0.750) \\
0.738\end{array}$ & $10.0 \%$ & $95.2 \%$ & $50.0 \%$ & $69.0 \%$ & $67.7 \%$ & 0.816 \\
LSG & $10(100 \%)$ & $(0.567-0.909)$ & $100 \%$ & $47.6 \%$ & $47.6 \%$ & $100 \%$ & $64.5 \%$ & 0.035 \\
\hline
\end{tabular}

MRI-magnetic resonance, CT-computer tomography; LSG-lymphoscintigraphy, AUC—area under curve, $\mathrm{CI}-$ confidence interval, Sn-sensitivity, Sp-specificity, PPV-positive predictive value, NPV—negative predictive value. 


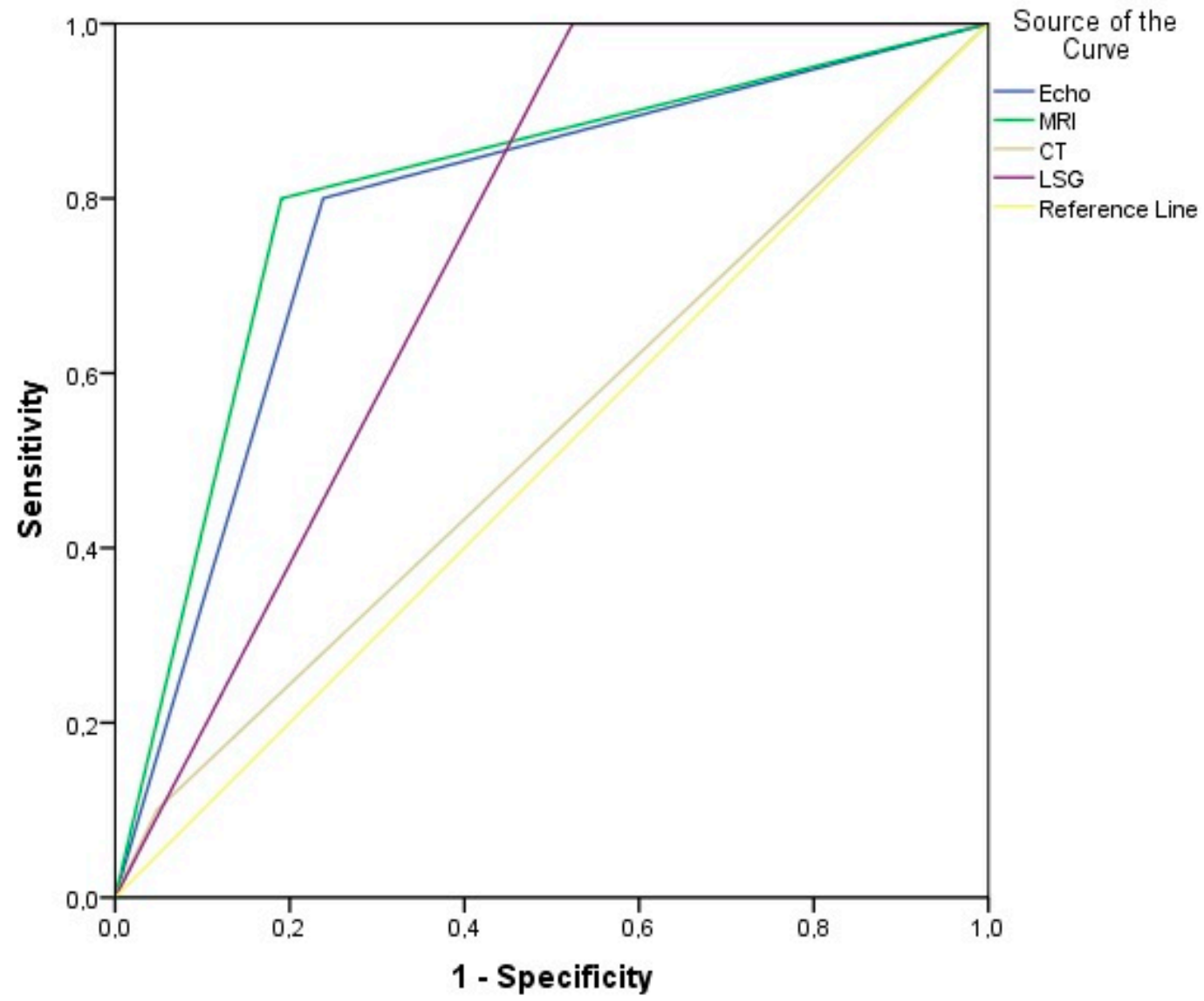

Figure 2. The ROC curve analysis to predict lymph node enlargement with four different diagnostic tools (echo-ultrasound, MRI, CT and LSG).

Afterwards, a sentinel node biopsy (SNB) was performed on 21 patients with a positive LSG finding due to the excellent sensitivity to detect true positive patients. Occult metastases using an SLNB were diagnosed in eight patients (38.1\%) with positive LSG results. All eight cases were confirmed by histopathology and had a pathology duration of over 1 year $(p=0.003)$, leading to an overall occult metastases rate of $25.8 \%$ out of all 31 enrolled patients. Higher age and lymph node enlargements were the only two risk factors that showed statistically significant association with occult metastases, as shown in Table 5.

Table 5. The predictive values for risk factor with calculated odds ratios (OR) with a $95 \%$ confidential interval (CI) for neck metastases.

\begin{tabular}{|c|c|c|c|c|c|c|c|}
\hline & $\begin{array}{c}\text { No Metastases } \\
\quad(n=23)\end{array}$ & $\begin{array}{l}\text { Metastases } \\
\quad(n=8)\end{array}$ & B & OR * & \multicolumn{2}{|c|}{$95 \%$ CI } & $p$-Value \\
\hline Age & $61.6 \pm 13.4$ & $63.6 \pm 14.7$ & 0.138 & 1.148 & 1.030 & 1.280 & 0.013 \\
\hline Gender M/F & $22 / 1(95.7 \% / 4.3 \%)$ & $6 / 2(75.0 \% / 25.0 \%)$ & -1.992 & 0.136 & 0.010 & 1.772 & 0.128 \\
\hline Profession & & & -0.109 & 0.896 & 0.559 & 1.436 & 0.649 \\
\hline Farmer & $10(43.5 \%)$ & $4(50.0 \%)$ & & & & & \\
\hline Housewife & $1(4.3 \%)$ & 0 & & & & & \\
\hline Machinist & $2(8.7 \%)$ & $1(12.5 \%)$ & & & & & \\
\hline Pensioner & $4(17.4 \%)$ & $2(25.0 \%)$ & & & & & \\
\hline Physical worker & $5(21.7 \%)$ & $1(12.5 \%)$ & & & & & \\
\hline Police officer & $1(4.3 \%)$ & 0 & & & & & \\
\hline TNM & & & 0.377 & 1.458 & 0.711 & 2.990 & 0.303 \\
\hline Tc1Nc0M0 & $14(60.9 \%)$ & $2(25.0 \%)$ & & & & & \\
\hline
\end{tabular}


Table 5. Cont.

\begin{tabular}{|c|c|c|c|c|c|c|c|}
\hline & $\begin{array}{c}\text { No Metastases } \\
(n=23)\end{array}$ & $\begin{array}{c}\text { Metastases } \\
\quad(n=8)\end{array}$ & B & OR * & \multicolumn{2}{|c|}{$95 \%$ CI } & $p$-Value \\
\hline & $2(0.170)$ & $4(30.0 \%)$ & & & & & \\
\hline Tc2Nc1M0 & $2(8.7 \%)$ & $2(25.0 \%)$ & & & & & \\
\hline Tumor size & & & -0.272 & 0.762 & 0.122 & 4.751 & 0.771 \\
\hline $\mathrm{T} 1$ & $16(69.6 \%)$ & $6(75.0 \%)$ & & & & & \\
\hline $\begin{array}{c}\text { Lymph node enlargement } \\
\text { Risk factors }\end{array}$ & $2(8.7 \%)$ & $6(75.0 \%)$ & 2.657 & 14.250 & 2.069 & 98.140 & 0.007 \\
\hline Sun exposure & $10(43.5 \%)$ & $5(62.5 \%)$ & 0.773 & 2.167 & 0.415 & 11.302 & 0.359 \\
\hline Smoking & $18(78.3 \%)$ & $4(50.0 \%)$ & -1.281 & 0.278 & 0.051 & 1.526 & 0.141 \\
\hline Alcohol & $5(21.7 \%)$ & $1(12.5 \%)$ & -0.665 & 0.514 & 0.051 & 5.221 & 0.574 \\
\hline Family history & $3(13.0 \%)$ & $2(25.0 \%)$ & 0.799 & 2.222 & 0.298 & 16.558 & 0.436 \\
\hline
\end{tabular}

$\mathrm{M}$-male, F-female. * odds ratios (OR) were calculated with logistic regression, where the presence of metastasis presented the dependent variable. B value was determined as a correlation coefficient between the independent and dependent variables.

\section{Discussion}

Patients who were suffering from stage T1 and T2 SCC of the lower lip were followed-up over 2 years. The current study aimed to detect lower lip SCC tumors that had metastasized to the lymph nodes, to evaluate the accuracy of the diagnostic tools for lymph node enlargements (echo-ultrasound, MRI, CT and LSG) and to answer the thesis of whether elective or supraomohyoid neck dissection was necessary for patients with T1 or T2-stage lip cancer after evaluation of the SLNB.

The study included 31 patients whose demographic characteristics with a mean age of 61.6 years were comparable with the literature $[25,26]$. The majority were men and had been exposed to the sun and had smoking habits, which coincide with the knowledge of potential risk factors $[1,6]$. There are many risk factors for developing lip cancer, including higher age (especially for 60-70-year-olds), male gender, chronic exposure to sun radiation, tobacco and alcohol consumption, viral factors such as Human Papilloma Virus (HPV) 16 and 24, and Herpes Virus (HSV) 1 and 2 and accompanied autoimmune diseases and immunosuppressant drugs $[6,27,28]$. Farmers were also detected as a risk group of people for cutaneous SCC. This might be explained due to their sun exposure while working outside in the fields. In a case report by Nguyen et al. [29], a patient with SCC was also a farmer and often worked in sunlight. He had also smoked and consumed a great deal of alcohol for a long time.

Our results showed that the majority of patients $(n=22 ; 71.0 \%)$ in the current report had T1 stage SCC. Lymph node enlargements (Nc1) were discovered in 10 patients (32.3\%). Meanwhile, positive ultrasound, MRI, CT and LSG were detected in 13, 12, 2 and 21 patients, respectively. Therefore, ROC analysis showed the highest accuracy for detecting Nc1 with MRI (80.7\%), but LSG showed excellent sensitivity $(100 \%)$ and negative predictive value $(100 \%)$ for Nc1. That means that LSG was the test with the highest probability for detecting patients with true positive lymph node enlargements (Nc1). With different values for the diagnostic tools, we can confirm the findings from the literature that several factors may influence a misdiagnosis: a low incidence of lymph node metastasis, slow diffusion, deep metastasis, lymph node jump, fixation of the lymph node metastasis to the mandibular periosteum, and previous radiotherapy. Several factors are directly correlated to lymph node involvement, including tumor size and differentiation [12,13,30-32].

An SLNB was thus performed in all 21 patients with a positive LSG finding. Occult metastases were diagnosed in eight (38.1\%) patients leading to an overall occult metastasis in $25.8 \%$ out of 31 enrolled patients. Interestingly, two (25\%) out of eight patients had Nc0 and had developed metastases. Moreover, out of eight patients, six $(75 \%)$ had a T1 size tumor and two $(25 \%)$ did not have lymph node enlargements. The question arises: should patients with $\mathrm{T} 1$ and $\mathrm{Nc} 0$ avoid neck dissection? The management of patients with SCC with a clinically negative neck remains debatable, and the majority of clinicians prefer an elective neck dissection instead of a "wait-and-see" strategy due to the high 
rates of occult metastases [33]. However, almost 70\% $(n=21)$ of our patients had N0 and could be theoretically over-treated with a selective neck dissection [34].

Diagnostic developments have led to more extensive use of SLNB [35]. In modern surgical treatment, the presence of regional lymph node metastases is evaluated by the identification and examination of the sentinel lymph nodes [33,36]. The concept of an SLNB provides the possibility of accurate pathological node staging, whilst minimizing the invasiveness of the procedure and its associated morbidity. In addition, preoperative LSG and intraoperative detection have the additional advantage of identifying aberrant drainage pathways [34,37]. In the present study, 21 patients had positive findings but only eight were truly diagnosed. Therefore, SLNB shows the benefits of concentrating only on the relevant nodes for pathological examination. This selection allows for a more in-depth evaluation of patients and the small number of sentinel nodes, who truly develop occult metastases [37].

The sensitivity of the SLNB for head and neck cancer varies in the literature between $75 \%$ and $100 \%$. This has to be compared with the rate of regional recurrence after a selective neck dissection, which is recorded in the literature as between 6\% and 30\% [38-40]. In the present study, we did not calculate the sensitivity of SLNB but in a study by Sagheb et al. [41] the sensitivity was shown to be $75 \%$. Although further studies are necessary to confirm the results, patients with cN0 and early-stage SCC may benefit from an SLNB by avoiding the morbidity of a neck dissection. Although a selective neck dissection is less invasive than a radical dissection, high morbidity for the patients does exist, including shoulder dysfunction, contour changes, pain and lower lip paresis [42-44]. Although selective neck dissection has proven reliability and worldwide acceptance, it is an extended surgery compared to SLNB, involving a longer surgical time, higher costs and greater morbidity. Functional outcomes and postoperative complications following an SLNB are also significantly better than after a selective neck dissection [45,46]. In a study by Civantos [34], the authors evaluated the NPV for SLNB. For T1 lesions, the NPV was 100\%. The authors concluded that SLNB as a procedure was more suited for smaller lesions, and with an overall NPV of $96 \%$ for T1 or T2 N0 oral SCC, they correctly predicted a pathologically negative neck in $96 \%$ of patients. Thus, a negative SLNB would only result in the neck of $4 \%$ of patients.

Modern diagnostic developments and reports could enhance the clinical application of SLNB. We could argue that the presented results suggest that if SLNB is applied initially in an appropriately low-risk group, the procedure provides reasonable results. The effect of the procedure on the smaller group of only eight true positives is also an issue because the pathologic status of the sentinel node is sometimes not known until days after surgery. Given that the "watch-and-see" approach persists for selected T1 and T2 lesions and that some patients have circumstances that make the moderate morbidities of neck dissection unacceptable, it is likely that there may be a role for SLNB as a replaceable option. In conclusion, we suggest, but with speculation and great caution, that the SLNB is reasonable to initiate only for patients with positive sentinel nodes by positive LSG, as a lower morbidity approach for selected patients with T1 and T2 stage cancers.

However, our study had some limitations. A limitation was that the SLNB might have changed the way the neck dissection was performed. Our study design may actually lead to an underestimation of the accuracy of this technique relative to selective neck dissection, since the metastatic tumor can be left behind after an SLNB, thus requiring a further neck dissection. Such an issue was not addressed in our study design. Therefore, we should have followed our patients for a much longer time than just 2 years. Other limitations include the fact that we only detected eight cases of metastatic lymph nodes. The study presents only a small sample size of cases, so in the future a much larger study period with a much more extended follow-up period will be necessary. We have also not evaluated the predictive values for SLNB as a treatment option compared to neck dissection. In the future, more research should be conducted on this aspect. 


\section{Conclusions}

Minimal damage of tissue and motoric functions are approaches that are becoming commonplace to reduce surgical morbidity. Neck dissection has always been a procedure that has resulted in high morbidities for the patients. SLNB is thus a less invasive approach and provides timely information regarding the status of the neck, and it is likely to be an attractive option for patients and physicians. Although further studies are necessary to confirm the results, patients with cN0 and early T1 or T2 stage SCC may benefit from an SLNB by avoiding the morbidity of a neck dissection. However, according to our results, with great caution, we suggest that SLNB is reasonable to initiate only for patients with positive sentinel nodes by positive LSG, as a lower morbidity approach for selected patients with T1 and $\mathrm{T} 2$ stage cancers.

Author Contributions: Conceived and designed the experiments: M.P.L., S.R. Acquisition of the data: M.P.L., S.R. Analysis and Interpretation of the data: M.P.L., D.S., T.J., S.R. Drafting of the manuscript: M.P.L., D.S., T.J., S.R. Critical revision of the manuscript for important intellectual content: D.S., T.J., S.R. Statistical analysis: D.S., T.J. Supervision: M.P.L. All authors have read and agreed to the published version of the manuscript.

Funding: The study received no funding.

Conflicts of Interest: The authors declare no conflict of interest.

\section{References}

1. Han, A.Y.; Kuan, E.C.; Mallen-St Clair, J.; Alonso, J.E.; Arshi, A.; St John, M.A. Epidemiology of Squamous Cell Carcinoma of the Lip in the United States: A Population-Based Cohort Analysis. JAMA Otolaryngol. Head Neck Surg. 2016, 142, 1216-1223. [CrossRef]

2. Zitsch, R.P., 3rd; Park, C.W.; Renner, G.J.; Rea, J.L. Outcome analysis for lip carcinoma. Otolaryngol. Head Neck Surg. 1995, 113, 589-596. [CrossRef]

3. Neville, B.W.; Damm, D.D.; Allen, C.M.; Bouquot, J.E. Oral \& Maxillofacial Pathology, 2nd ed.; W.B. Saunders: Philadelphia, PA, USA, 2002; pp. 337-369.

4. Martinez, J.C.; Cook, J.L. High-risk cutaneous squamous cellcarcinoma without palpable lymphadenopathy: Is there a therapeutic role for elective neck dissection? Dermatol. Surg. 2007, 33, 410-420.

5. Mourouzis, C.; Boynton, A.; Grant, J.; Umar, T.; Wilson, A.; Macpheson, D.; Pratt, C. Cutaneous head and neck SCCs and risk of nodal metastasis-UK experience. J. Craniomaxillofac. Surg. 2009, 37, 443-447. [CrossRef]

6. Maruccia, M.; Onesti, M.G.; Parisi, P.; Cigna, E.; Troccola, A.; Scuderi, N. Lip cancer: A 10-year retrospective epidemiological study. Anticancer. Res. 2012, 32, 15436.

7. Grimaldo-Carjevschi, M.; López-Labady, J.; Villarroel-Dorrego, M. Squamous cell carcinoma on the palate in a patient with systemic lupus erythematosus: Case report and review of literature. Lupus 2011, 20, 519-522. [CrossRef]

8. Lydon, E.J.; Belmont, H.M. When rectal bleeding is serious: Anal squamous cell carcinoma in two intravenous cyclophosphamide treated systemic lupus erythematosus patients with human papilloma virus infection. Lupus 2013, 22, 1182-1184. [CrossRef]

9. Takeda, A.; Akimoto, M.; Nemoto, M.; Kounoike, N.; Uchinuma, E. Preoperative risk factors of lymph node metastasis in cutaneous squamous cell carcinoma. J. Plast. Surg. Hand Surg. 2013, 47, 204-208. [CrossRef]

10. Dediol, E.; Luksic, I.; Virag, M. Treatment of squamous cell carcinoma of the lip. Coll. Antropol. 2008, 32, 199-202.

11. Morselli, P.; Masciotra, L.; Pinto, V.; Zollino, I.; Brunelli, G.; Carinci, F. Clinical parameters in T1N0M0 lower lip squamous cell carcinoma. J. Craniofac. Surg. 2007, 18, 1079-1082. [CrossRef]

12. Gooris, P.J.; Vermey, A.; de Visscher, J.G.; Burlage, F.R.; Roodenburg, J.L. Supraomohyoid neck dissection in the management of cervical lymph node metastases of squamous cell carcinoma of the lower lip. Head Neck 2002, 24, 678-683. [CrossRef]

13. Kornevs, E.; Skagers, A.; Tars, J.; Bigestans, A.; Lauskis, G.; Libermanis, O. 5-year experience with lower lip cancer. Stomatologija 2005, 7, 95-98.

14. Szewczyk, M.; Pazdrowski, J.; Golusiński, P.; Dańczak-Pazdrowska, A.; Marszałek, S.; Golusiński, W. Analysis of selected risk factors for nodal metastases in head and neck cutaneous squamous cell carcinoma. Eur. Arch. Otorhinolaryngol. 2015, 272, 3007-3012. [CrossRef] 
15. Hasson, O. Squamous cell carcinoma of the lower lip. J. Oral Maxillofac. Surg. 2008, 66, 1259-1262. [CrossRef]

16. Kuscu, O.; Bajin, M.D.; Süslü, N.; Hosal, A.S. The role of suprahyoid neck dissection in the treatment of squamous cell carcinoma of the lower lip: 20 years' experience at a Tertiary Center. J. Craniomaxillofac. Surg. 2016, 44, 1404-1407. [CrossRef]

17. Rapoport, A.; Ortellado, D.K.; Amar, A.; Lehn, C.N.; Dedivitis, R.A.; Perez, R.S.; Rodrigues, H.M. Radical versus supraomohyoid neck dissection in the treatment of squamous cell carcinoma of the inferior level of the mouth. Braz. J. Otorhinolaryngol. 2007, 73, 641-646. [CrossRef]

18. Ng, S.H.; Ko, S.F.; Toh, C.H.; Chen, U.L. Imaging of neck metastases. Chang Gung Med. J. 2006, $29,119-129$.

19. Altinyollar, H.; Berberoglu, U.; Celen, O. Lymphatic mapping and sentinel lymph node biopsy in squamous cell carcinoma of the lower lip. Eur. J. Surg. Oncol. 2002, 28, 72-74. [CrossRef]

20. Morton, D.L. Overview and update of the phase III Multicenter Selective Lymphadenectomy Trials (MSLT-I and MSLT-II) in melanoma. Clin. Exp. Metastasis 2012, 29, 699-706. [CrossRef]

21. Kwon, S.; Dong, Z.M.; Wu, P.C. Sentinel lymph node biopsy for highrisk cutaneous squamous cell carcinoma: Clinical experience and review of literature. World J. Surg. Oncol. 2011, 9, 80. [CrossRef]

22. Ahmed, M.M.; Moore, B.A.; Schmalbach, C.E. Utility of head and neck cutaneous squamous cell carcinoma sentinel node biopsy: A systematic review. Otolaryngol. Head Neck Surg. 2014, 150, 180-187. [CrossRef]

23. Tsujino, Y.; Mizumoto, K.; Matsuzaka, Y.; Niihara, H.; Morita, E. Fluorescence navigation with indocyanine green for detecting sentinel nodes in extramammary Paget's disease and squamous cell carcinoma. J. Dermatol. 2009, 36, 90-94. [CrossRef]

24. Fujisawa, Y.; Nakamura, Y.; Kawachi, Y.; Otsuka, F. Indocyanine green fluorescence-navigated sentinel node biopsy showed higher sensitivity than the radioisotope or blue dye method, which may help to reduce false-negative cases in skin cancer. J. Surg. Oncol. 2012, 106, 41-45. [CrossRef]

25. Hashibe, M.; Brennan, P.; Benhamou, S.; Castellsague, X.; Chen, C.; Curado, M.P. Alcohol drinking in never users of tobacco, cigarette smoking in never drinkers and the risk of head and neck cancer: Pooled analysis in the international head and neck cancer epidemiology consortium. J. Natl. Cancer Inst. 2007, 99, 777-789. [CrossRef]

26. Petti, S. Lifestyle risk factors for oral cancer. Oral Oncol. 2009, 45, 340-350. [CrossRef]

27. Galyon, S.W.; Frodel, J.L. Lip and perioral defects. Otolaryngol. Clin. N. Am. 2001, 34, 647-666. [CrossRef]

28. Veness, M.J. High-risk cutaneous squamous cell carcinoma of the head andneck. J. Biomed. Biotechnol. 2007, 2007, 80572. [CrossRef]

29. Nguyen, H.X.; Nguyen, H.V.; Nguyen, H.X.; Le, Q.V. Lower lip squamous cell carcinoma: A Vietnamese case report of surgical treatment with reconstruction by local flap. Int. J. Surg. Case Rep. 2018, 53, 471-474. [CrossRef]

30. Vukadinovic, M.; Jezdic, Z.; Petrovic, M.; Medenica, L.M.; Lens, M. Surgical management of squamous cell carcinoma of the lip: Analysis of a 10-year experience in 223 patients. J. Oral Maxillofac. Surg. 2007, 65, 675-679. [CrossRef]

31. Dunne, A.A.; Budach, V.G.; Wagner, W.; Werner, J.A. Management of N0 neck in head and neck cancer: Current controversies. Onkologie 2004, 27, 363-367. [CrossRef]

32. Bucur, A.; Stefanescu, L. Management of patients with squamous cell carcinoma of the lower lip and N0-neck. J. Craniomaxillofac. Surg. 2004, 32, 16-18. [CrossRef] [PubMed]

33. Chone, C.T.; Magalhes, R.S.; Etchehebere, E.; Camargo, E.; Altemani, A.; Crespo, A.N. Predictive value of sentinel node biopsy in head and neck cancer. Acta Otolaryngol. 2008, 128, 920-924. [CrossRef] [PubMed]

34. Civantos, F.J.; Zitsch, R.P.; Schuller, D.E.; Agrawal, A.; Smith, R.B.; Nason, R. Sentinel lymph node biopsy accurately stages the regional lymph nodes for T1-T2 oral squamous cell carcinomas: Results of a prospective multi-institutional trial. J. Clin. Oncol. 2010, 28, 1395-1400. [CrossRef] [PubMed]

35. Kuriakose, M.A.; Trivedi, N.P. Sentinel node biopsy in head and neck squamous cell carcinoma. Curr. Opin. Otolaryngol. Head Neck Surg. 2009, 17, 100-110. [CrossRef]

36. Stoeckli, S.J.; Alkureishi, L.W.; Ross, G.L. Sentinel node biopsy for early oral and oropharyngeal squamous cell carcinoma. Eur. Arch. Otorhinolaryngol. 2009, 266, 787-793. [CrossRef]

37. Alkureishi, L.W.; Ross, G.L.; Shoaib, T.; Soutar, D.S.; Robertson, A.G.; Thompson, R. Sentinel node biopsy in head and neck squamous cell cancer: 5-year follow-up of a European multicenter trial. Ann. Surg. Oncol. 2010, 17, 2459-2464. [CrossRef] 
38. Fasunla, A.J.; Greene, B.H.; Timmesfeld, N.; Wiegand, S.; Werner, J.A.; Sesterhenn, A.M. A meta-analysis of the randomized controlled trials on elective neck dissection versus therapeutic neck dissection in oral cavity cancers with clinically node-negative neck. Oral Oncol. 2011, 47, 320-324. [CrossRef]

39. Liu, T.R.; Chen, F.J.; Yang, A.K.; Zhang, G.P.; Song, M.; Liu, W.W.; Chen, W.C.; Chen, Y.F.; Ouyang, D.; Li, Q.L. Elective neck dissection in clinical stage I squamous cell carcinoma of the tongue: Does it improve regional control or survival time? Oral Oncol. 2011, 47, 136-141. [CrossRef]

40. Ebrahimi, A.; Ashford, B.G.; Clark, J.R. Improved survival with elective neck dissection in thick early-stage oral squamous cell carcinoma. Head Neck 2012, 34, 709-716. [CrossRef]

41. Sagheb, K.; Sagheb, K.; Rahimi-Nedjat, R.; Taylor, K.; Al-Nawas, B.; Walter, C. Sentinel lymph node biopsy in T1/T2 squamous cell carcinomas of the tongue: A prospective study. Oncol. Lett. 2016, 11, 600-604. [CrossRef]

42. Nibu, K.; Ebihara, Y.; Ebihara, M.; Kawabata, K.; Onitsuka, T.; Fujii, T.; Saikawa, M. Quality of life after neck dissection: A multicenter longitudinal study by the Japanese clinical study group on standardization of treatment for lymph node metastasis of head and neck cancer. Int. J. Clin. Oncol. 2010, 15, 33-38. [CrossRef]

43. Terrell, J.E.; Ronis, D.L.; Fowler, K.E.; Bradford, C.R.; Chepeha, D.B.; Prince, M.E.; Teknos, T.N.; Wolf, G.T.; Duffy, S.A. Clinical predictors of quality of life in patients with head and neck cancer. Arch. Otolaryngol. Head Neck Surg. 2004, 130, 401-408. [CrossRef]

44. Ferlito, A.; Rinaldo, A.; Silver, C.E.; Gourin, C.G.; Shah, J.P.; Clayman, G.L. Elective and therapeutic selective neck dissection. Oral Oncol. 2006, 42, 14-25. [CrossRef]

45. Murer, K.; Huber, G.F.; Haile, S.R.; Stoeckli, S.J. Comparison of morbidity between sentinel node biopsy and elective neck dissection for treatment of the $\mathrm{n} 0$ neck in patients with oral squamous cell carcinoma. Head Neck 2011, 33, 1260-1264. [CrossRef]

46. Schiefke, F.; Akdemir, M.; Weber, A.; Akdemir, D.; Singer, S.; Frerich, B. Function, postoperative morbidity and quality of life after cervical sentinel node biopsy and after selective neck dissection. Head Neck 2009, 31, 503-512. [CrossRef]

(C) 2020 by the authors. Licensee MDPI, Basel, Switzerland. This article is an open access article distributed under the terms and conditions of the Creative Commons Attribution (CC BY) license (http://creativecommons.org/licenses/by/4.0/). 